\title{
Study of superficial layers obtained by selective transfer in the friction couples
}

\begin{abstract}
The paper surveys current trends in systematizing bone and antler industries dated back to the 5th-1st millennia BC in the North Pontic area. The principles in question, however, seem to be adaptable to any of the many bone and antler contents of the Earth's archaeosphere. The reader is introduced to the classificatory concept of the author's own work which has never been explicated in full elsewhere. Usually, the North Pontic archaeologists definitely wish their archaeological record to be imposed into given classification completely. Yet the latter normally contains impermeable inherent limits set up by the analysts themselves, who basically face a scarcity of comprehensive expert data. Here, a solution to the problem is put forward based on systemic classificatory approach. This one refers to the osseous raw material structures and the ways these latter were bound to transform during manufacture. The author's techno classes concept of adapting, modifying and converting bone and antler during utilization goes back, in particular, to A.P. Borodovskiy's technological systematics. The traceology, in its turn, tends to embed almost anything identifiable into a system, since various means of functional analysis would be a bit of a help as verifying methods. At the same time, the artifact's technical function and the manner it was used are the issues of special research concern. Further, the ways in which past equipments (instruments, implements and accessories) might have affected other objects and substances or interacted with them, resulted in rational shapes and usewear patterns in artifacts of bone and antler. On that basis, tools, devices, joints, furniture and paraphernalia entities seem to be quite perceptive to the variability of the North Pontic worked osseous record. This kind of arrangement of the material, would it be derived from a site or an archaeological culture, may have been flexibly changed in terms of its units, whereas its principal sections are here to stay with no need them to be rearranged.
\end{abstract}

Keywords: north pontic area, the chalcolithic, the bronze age, the iron age, bone and antler industry, classification, traceology
Volume 2 Issue 5 - 2017

\section{Filip Ilie}

Department of Machine Elements and Tribology, Polytechnic

University of Bucharest, Romania

Correspondence: Filip llie, Department of Machine Elements and Tribology, Polytechnic University of Bucharest, Romania, Tel 00402 I 40294II, Fax 00402I 402958I,

Email ilie.filip@yahoo.com

Received: May 15, 2017 | Published: June 02, 2017

\section{Introduction}

The selective transfer phenomenon is based on physic-chemical processes, which takes place in the contact zones of the friction couples which assure a thermodynamic instability of the lubricant and which allow the transfer of some materials. This transfer is achieved if there is a favorable energy and in the presence of relative movement, if in the friction zone is a material made by copper and the lubricant is adequate (glycerin or special lubricant). ${ }^{1-3}$

Phenomenological the selective transfer phenomenon includes follows:

i. Reduction of the contact pressure as a result of enlarging friction surface.

ii. Compensation of tangential tensions by selective dissolving of a thin, superficial layer formed by the two materials in contact.

iii. The coming back of the particles removed by worn out in the friction zone and forming a thin, polymerized, protection layer.

This layer has the property that it assures an agglomeration of dislocations in deformation processes, in a way specific to the malleable materials and this way to protect the layer against destruction. ${ }^{4}$ The selective dissolution of the copper alloy elements provokes about in the crystalline network of this solid solution as in the chemical compounds a surplus of defects. Moreover, defects appear at the deformation of superficial zones and at the exit of dislocations from surface. ${ }^{5,6}$ The thickness of this layer is very small $(1 \ldots 5 \mu \mathrm{m})$ and it is extremely porous, thus its size are compared with the field of dislocation tensions.

\section{Researching method for the thin superficial layers}

Experimental researches regarding selective transfer revealed that on the friction surface forms a thin layer rich in copper that depends on working conditions.

The forming of this layer on the contact surfaces makes that the friction force to be decrease because of the structure formed by selective transfer between metallic layers from the surfaces. The research method is recommended to be made by structural analysis with X-rays. ${ }^{7-11}$ The metallic layer, which usually participates in the interaction with the X-rays and from which come the structural information, has a thickness of $10^{-1} \ldots 10^{-3} \mathrm{~mm} .^{9}$ Similar information is can obtain and by the study superficial layers by diffraction with electrons. ${ }^{12-15}$ By this method is can research a thickness of $10^{-}$ ${ }^{5} \ldots 10^{-6} \mathrm{~mm}$. In the refs. ${ }^{7,9,11}$ Describe a research method of the solid bodies' structure by structural analysis with X-rays with the variable incidence of the ray fascicle, which makes possible the investigation 
of thin metal layers with a thickness of $10^{-3} \ldots 10^{-5} \mathrm{~mm}$. The way of the radiation through metal is composed by the way of incident ray $r_{i}=h / \sin \alpha$ and the scattered ray $r_{d}=h / \sin (2 \theta-\alpha)$, where $h$-is the depth of penetration of the ray in the material and is calculated with the relationship:

$$
h=\frac{r_{i} / \mathrm{r}_{d}}{\mu}-\frac{\sin \alpha-\sin (2 \theta-\alpha)}{\sin \alpha+\sin (2 \theta-\alpha)}
$$

With: $\mu$ - linear coefficient of absorption; $\alpha$ - angle of inclination between the research surface and the incidence ray; $\theta$ - dispersion angle. From relation (1) we can notice that the thick of the researched metallic layer is determined by the angle of inclination of rays which fall on the sample surface Figure 1.

In Table 1 are shown the results determining the layer thickness of copper $\mathrm{h}$, participant in the reflection, for different incidence angles of the incident fascicle on the surface of the sample for Co radiations.

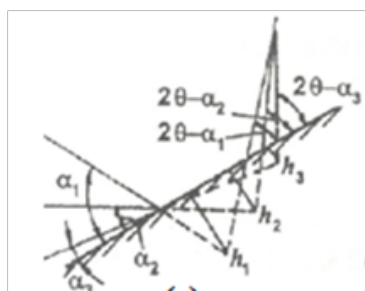

(a)

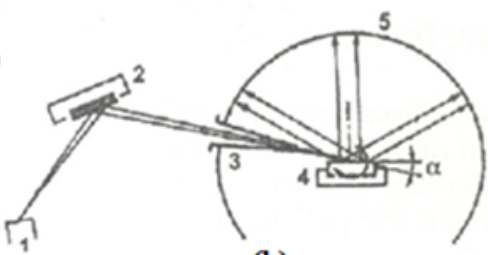

(b)
Figure I Research principle of the metallic layers with the help of the method of the rays fascicle with variable angle (A); research principle (B): anode with outbreak - I; monochromator with crystal - 2; collimator - 3; sample - 4; detector (image viewer)-5.

Table I Thickness layer of copper

\begin{tabular}{|c|c|c|c|c|c|c|c|c|c|}
\hline \multirow[t]{2}{*}{ Radiation } & \multirow{2}{*}{$\begin{array}{l}\text { Wave length } \\
\lambda[\mathrm{m}]\end{array}$} & \multirow[t]{2}{*}{$\theta$} & \multicolumn{7}{|c|}{$\mathrm{H}$ Values in $\mu \mathrm{m}$ For $\alpha$ Suitable, in Degrees } \\
\hline & & & $40^{\circ}$ & $30^{\circ}$ & $20^{\circ}$ & $10^{\circ}$ & $3^{\circ}$ & $2^{\circ}$ & $1^{\circ}$ \\
\hline Co & 1.789 & $25^{\circ} 24^{\prime}$ & 4.1 & 4.0 & 4.0 & 3.7 & 0.9 & 0.7 & 0.3 \\
\hline
\end{tabular}

Note: The calculation was made for the case when $75 \%$ from the radiation, which reaches on the surface are absorbed by the layers which participants in reflection.

We can notice that the modifying of the incident angle $\alpha$ in the domain from $40^{\circ}$ to $1^{\circ}$ lead to a reduction of the layer thickness by 13 times (from 4.1 to $0.4 \mu \mathrm{m}$ ). Therefore, by modify the wavelength of the radiation and incident angle is can research the layers structure on various depths.

By X-ray fascicle method with the variable incidence were researched samples bronze of aluminum/steel OL37 tested on Timken installation lubricated with glycerin, using the JXA-5A electronic microscope.

Before to be tested experimentally, the samples special manufactured, have been examined by analysis metallographic and chemical, with the purpose to know the structure in the crystalline network and chemical composition of alloying elements of bronze and steel that needs to be investigated. This thing had been made that after experimental, a new metallographic and chemical analysis of the steel samples on which transferred a layer by the bronze color to give information regarding the composition and the thickness of the superficial layer that shows up in the friction process in conditions of the selective transfer. ${ }^{2,10,12}$

The metallographic and chemical analysis of the steel samples with thin selective layer after they worked by friction in the selective transfer conditions shown that this layer has approximately the same structure and composition chemical with of the bronze where it came from. For example, if the aluminum bronze has about $83.5 \%$ $\mathrm{Cu}, 10 \% \mathrm{Al}, 3 \% \mathrm{Zn}, 2 \% \mathrm{Fe}, 2 \% \mathrm{Mn}, 0,3 \% \mathrm{~Pb}, 0,1 \% \mathrm{Sn}, 0.05 \% \mathrm{As}$, at the transferred layer on the steel sample has about $85 \% \mathrm{Cu}, 8.5 \%$ $\mathrm{Al}, 2 \% \mathrm{Zn}, 2 \% \mathrm{Fe}, 1.5 \% \mathrm{Mn}, 0.2 \% \mathrm{~Pb}, 0.05 \% \mathrm{Sn}$, therefore is made an increasing of copper percent to the prejudice of the other alloying elements.

Structural analysis was made with the help of Co radiation. The angle $\alpha$ can be modified from 1 degree to 40 degrees. This area corresponds reflection of the superficial layers with a thickness about
$0.2-5 \mu \mathrm{m}$. As a parameter for the structural modifying in superficial zones has been chosen the width of real line of interference $\beta$ being characteristic for pure metals and solid solutions, which are in balance. At the same time, it is a parameter for the dislocations density the existent in metal. ${ }^{2,3,16}$ In Figure 2 are shown the results regarding the modifying of the width of interference lines of the copper, at a different depth, after friction.

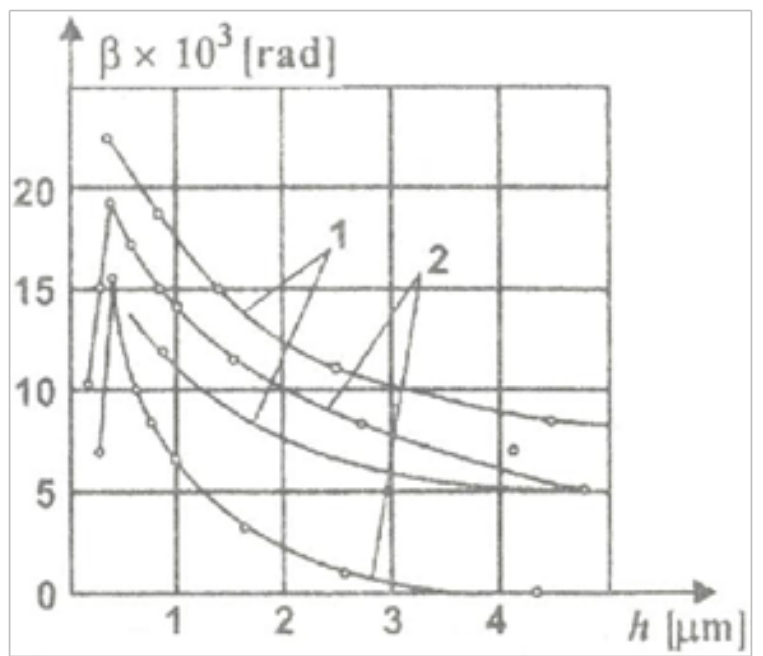

Figure 2 Variation of the diffraction lines width $\beta$ of the copper with the depth $\mathrm{h}$ after a 0.5 hours (I) and 35.5 hours (2) solicitation by friction.

We can notice that interference lines can do modified very much depending on depth reported at the surface of the samples (about three times). Also, we can notice in very thin superficial layers of the samples obtained through friction a large number of defects of the structure. In Figure 3 is shown the modification of the width of the diffraction lines $\beta$ in function of friction time.

At the beginning of the friction after about 5 minutes, the width of the lines is determined by the size of the pressure from contact zone, which provokes and structural changes into a metal. In a layer with the thickness $0.3 \mu \mathrm{m}$ the width of the diffraction lines lowers one 
time with of the testing duration. In layers with a thickness of 1.5 and $5.0 \mu \mathrm{m}$, then when the diffraction image is influenced by basic crystal, which is much more far from the surface, after 1-2hours, provokes only a little reduction of the width of the lines. After duration of testing of 35.5 hours, $\beta$ has changed very little. The decrease of the width of diffraction lines shows decreasing density of dislocations in the thin superficial layer of the copper-based alloy if it is researched after the friction solicitation. That helped to prove that at the friction in selective transfer conditions didn't appear an agglomeration of dislocations which in the next friction process would lead to destruction by fatigue of superficial layers. ${ }^{2,3,16}$ In Figure 4 is shown the variation of the network constant, a, at the aluminum bronze depending on of the depth $\mathrm{h}$ from the surface of sample in a zone of $5 \mu \mathrm{m}$ after a solicitation by friction with a pressure of $0.3 \mathrm{MPa}$

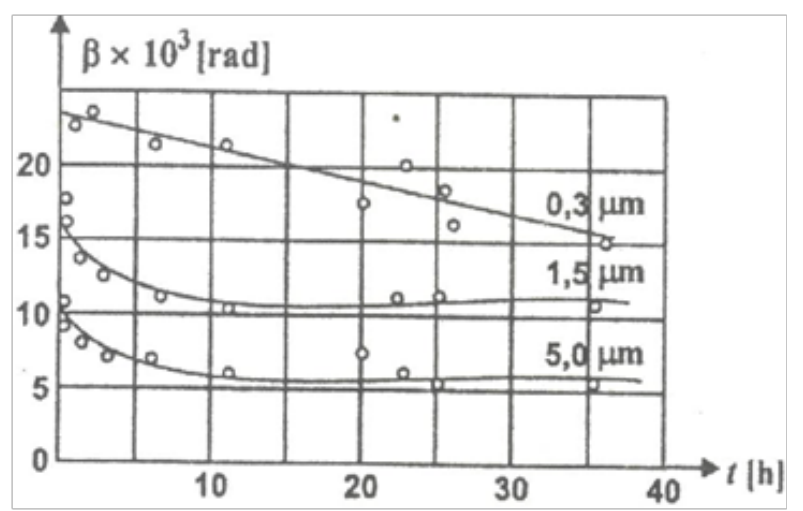

Figure 3 Variation of the width of the diffraction lines $\beta$ of the copper layers at different depths in function of friction time.
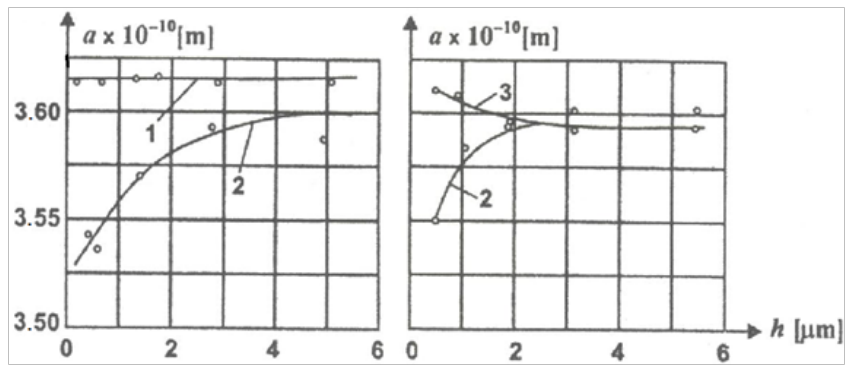

Figure 4 Variation of the network constant, a, at aluminum bronze in function of the depth $\mathrm{h}$ after a 0.5 hours $(\mathrm{A})$ and 2 hours $(\mathrm{B})$ solicitation by friction: I- at the depth of $5 \mu \mathrm{m} ; 2$ - after a solicitation by friction at pressure $0.3 \mathrm{MPa}$; 3-after a 0.5 hours heating at $70^{\circ} \mathrm{C}$.

It can be observed that for a short period of time ( 0.5 hours), the crystalline network constant, a, at the copper from zones that are near to friction surface, it is reduced and it only $3.53 \cdot 10^{-10} \mathrm{~m}$. Also, is ascertain that the network constant it changes after a supplementary heating of the sample if before was submitted to a friction solicitation.

The results regarding the modifying of the crystalline network constant of a sample from aluminum bronze, that submitted to a solicitation by friction for about 2 hours and after that it was warmed for 0.5 hours to $70^{\circ} \mathrm{C}$, are shown by the 3 curve from Figure 4 . We can notice that a supplementary warming brings network constant only in the superficial layers very thin to its initial size. In the deeper layers, network constant remains at little values. Therefore, the research with a supplementary warming shown that there is a connecting between smaller values of the network constant near to friction surfaces for a sample solicited by friction and the point-form defects, especially in the zones with defects.
Because, point-form defects have a bigger thermic activity they are removed faster from into a metallic body by friction at relatively reduced temperatures, as a following of warming than other defects. For copper, for example, this temperature isn't bigger than $150-200^{\circ} \mathrm{C}$.

Relatively low values, for the network constant a, in layers with a thickness bigger than $1 \mu \mathrm{m}$ were formed by the elastically compression tensions, what they are born during friction, for their removed is need of a temperature of warming bigger.

\section{Properties of superficial selective layers}

The distributions way of the temperature and pressure in more deep active layers and selective dissolving process, which are present at friction in the conditions of the selective transfer, influences and size of the existent forces from superficial zones, which provokes the diffusion process of metal atoms. The volume of redistribution of the alloying elements during the friction process may be appreciated by modifying network constant a. The accuracy of such an appreciation is given from the report of the atomically sizes of the alloying elements and of copper atom and is the evidently at of bronze analysis on tin based, on aluminum based or brass. In Figure 5 are shown the results of the crystalline network constant at aluminum bronze at different depths from friction surface to $5 \mu \mathrm{m}$, where we can clearly recognize that after friction solicitation the network constant of the alloys is considerably decreased. This thing is provoked by a poverty of the superficial layer in alloying elements $(\mathrm{Al}, \mathrm{Zn})$.

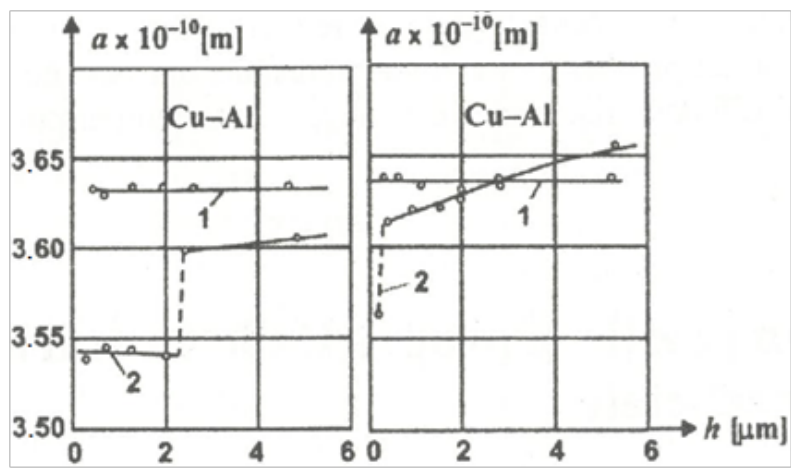

Figure 5 Variation of the network constant, a, at the aluminum bronze in function of the depth $\mathrm{h}$ from the friction surface after 2 hours solicitation by friction (A) and after a I - hour (B): I - initial state; 2 - copper layer.

At a such analysis of the superficial, thin layers, which had been effected at a small incidence angle of the radiation on surface, to result that on the diagrams of X-radiation intensity doesn't appear only one lines system how it happens usually, Figure 6, but it is noticeable two lines systems (Figure 6B \& 6C) which it corresponds to an interference at the crystallographic planes of two materials: of the copper layer and of the basic alloy. 2,3,16

The presence of two systems of lines in intensity diagrams of $\mathrm{X}$-rays shows the presence of a distinct limit between the layers formed at the surface and basic material of samples. From intensity ratio of the lines different materials can be appreciated the thickness of the layer formed at the surface in conditions of the selective transfer. Intensity diagrams of the X-rays (Figure 6B) have been obtain by photographing of the visualize image of the thin superficial layers obtained by selective transfer, enlarged by 300 times with photo camera within electronic microprobe.

The variation of lines system shows that the thickness of the selective layer (obtained by selective transfer) is not equal in all 
zones, after a direction (on the surface length or width coated with thin superficial layer by transfer selective), situated at a certain depth from contact surface (Table 1). The diagrams from Figure 6 have been determined at aluminum bronze/OL37 steel after the solicitation by friction of 2 hours lubricated with glycerin and at various loads and velocities. The way in which the thickness of the selective layer varies in different time, speed and load conditions, after 2 hours of work by friction is shown in Figure 7.

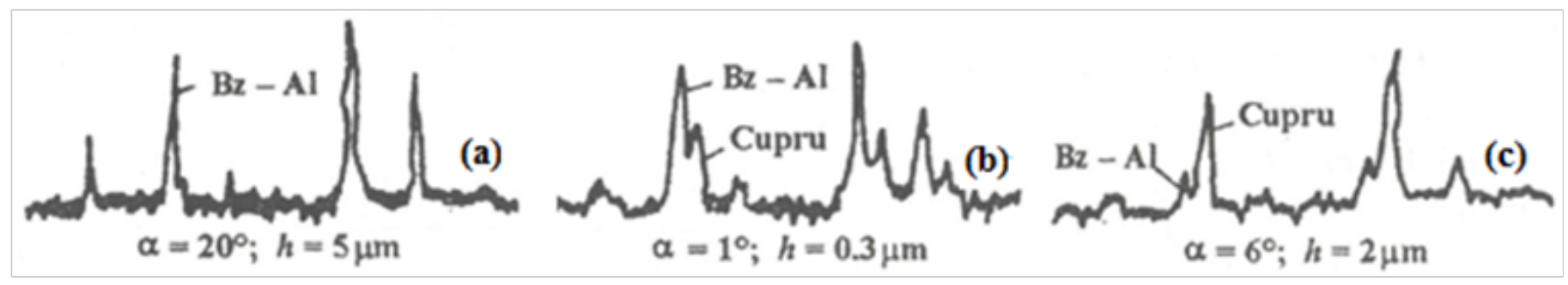

Figure 6 Intensity diagrams of the X-radiation at the aluminum bronze/steel OL 37 couple, after a 2 hours solicitation by friction, lubricated with glycerin: in the initial state (A); afterl hour (B) and after 2 hours of friction solicitation with selective transfer (C).

It can be noticed that the layer thickness increases in time until touches an optimal value, after which oscillates around of this value, what shows that the selective transfer takes place and inverse (Figure 7A). Also, the layer thickness increases with load $(<20 \mathrm{~N})$ until touches a maximal value, after which decrease very little with the load growing and with the tendency of stabilization for loads $>40 \mathrm{~N}$, after an operating time of 2 hours (Figure 7B). After how to result from intensity ratios of the diffraction lines, the thickness of transferred layer after a testing of 2 hours is about $2 \mu \mathrm{m}$. A quantitative appreciation regarding the thickness of the superficial, selective layers shows the growing in time until touches the maximum, after which the transfer is produced in the opposite direction remaining in function of time, within the limits of $2-3 \mu \mathrm{m}$, but oscillates very much. It can be reduced by 10 times and then to grow up again. These modifications of the thickness of layer correspond the observations on samples of steel OL37 which worked together with the copper based alloys by friction, tested on Timken installation, where the copper is linked by selective transfer on steel surface.
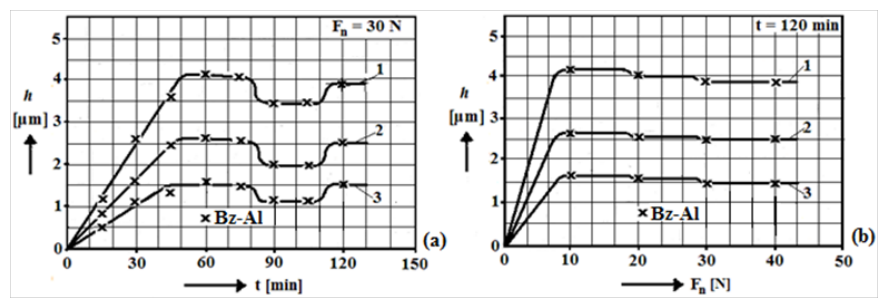

Figure 7 Variation of the thickness of the layer made by selective transfer in the presence of glycerin in function of friction time $t$ of the aluminum bronze at different sliding velocities and constant load $(A)$ in function of load $F_{n}$ and constant friction time for different sliding velocities (curves I at $0.93 \mathrm{~m} / \mathrm{s}$; curves 2 at $1.86 \mathrm{~m} / \mathrm{s}$; and curves 3 at $3.72 \mathrm{~m} / \mathrm{s}$ ).

\section{Conclusion}

Research realized by the structural analysis with X-rays on friction surfaces from copper alloy together with steel, lubricated with glycerin and in relative movement, after a friction solicitation make possible the elucidation of structural modifying and getting information regarding the mechanism of the behavior a metal in conditions of the selective transfer.

The dislocations density can be estimated from the width of diffraction lines and has rather big values in the thin layers, and in already known friction conditions even maximal values. Then, appears a decrease and ascertains reduction of the width of diffraction lines. The decrease of the dislocations density in the layers close to the surface is the provoked by the plasticizing effect of adsorption.

During the friction process there takes place in the conditions of the selective transfer in general, two processes at the same time: forming a thin layer of friction with special properties and forming of a limit between the superficial layer and basic body. At the same time, the maximum defects of the structure it's moving in the zones deeper of the layer. This proves a change of the thickness of the superficial layer in the formation.

The decomposition products of glycerin, which acts as tensionactive substances, decrease the superficial free energy as soon as they are adsorbed on the friction surface. By this facilitates the exit of dislocations from surface in the contact area. On the other hand, the research made shown up that the network constant, a, of the copper layer formed on the surface has $3.56 \cdot 10^{-10} \mathrm{~m}$ and is close to the theoretical value $3.615 \cdot 10^{-10} \mathrm{~m}$. These results are confirmed by friction tests and correspond to the data from specialty literature, ${ }^{16,17}$ at a fast solidifying of the copper from the liquid state, where $\mathrm{a}=3.54 \cdot 10^{-10} \mathrm{~m}$. A small network constant indicates a porosity of the superficial layers which formed during the friction process.

The results regarding the analysis of structural modifying in superficial thin layers prove that a selective transfer is characterized by certain structural transformations. This represents a necessary condition for the process of a state without wear. In this condition is included and the forming of a pure copper layer with special properties on the friction surface, in which dislocations density is higher as well as a bigger number of point-form defects. At the same time, it is reduced the amount of alloying elements in superficial layer too.

All experimental results show that the superficial, metallic, thin layers they're in a metal stable state, which is characterized by a very great loosening. All experimental results show that the superficial metallic thin layer is in a metastable state, characterized by a very great rarefaction. The big density of defects assures a large mobility of the atoms, which at their time provokes a diffusing mechanism of the defects in the form superior layer. This corresponds a state of the metal, in the friction surfaces zones, which is the similar of the fluid state. The big density of defects assures a large mobility of the atoms and provokes a diffusing mechanism of the defects in the form superior layer. This corresponds a metallic state, in the zones of the friction surfaces, which is the similar of the fluid state. For this reason, friction and wear behavior of friction couples operating with selective transfer is very good (comparable to fluid friction). 


\section{Acknowledgements}

None.

\section{Conflict of interest}

The author declares no conflict of interest.

\section{References}

1. F Ilie. A method of determining the thickness of the thin layers performing tribologically. J Balk Tribol Asso. 2012;18(3):357-364.

2. F Ilie. Study tribological of thin superficial layers formed in the friction couples through selective transfer. Technical Publishing House, Bucharest. Romania, 2002.

3. DN Garkunov. Erhohunug der Verschleibfestigkeit auf der Grudlage der selektiven Ubertragung. UEB Verlag, Technik. Berlin, 1981.

4. JP Hirth, J Lothe. Theory of Dislocations. New York: McGraw Hill Book Company; 1978.

5. VI Savenko, ED Sukin. O sootnosemiah mejdu fenomenologoceskimi i strukturnimi kriteriiami raboti uzlov trenia. Trenie i iznos $\mathrm{T}$. 1987;8(4):581-589.

6. F Ilie. Thermo-Mechanical Aspects of the Phenomenon of Selective Mass Transfer by Diffusion in Friction Process of Steel/Copper Alloy Couple. J of Multidiscipl Eng Sci Tech. 2015;2(2):70-75.

7. LM Rybakova, LI Kuksenova. X-ray Investigation of the Surface Layers of Metal Subjected to Friction in Conditions of Selective Transfer. Nowear effect and tribotechnologies. 1992;54-65.
8. SK Chatterjee. Experimental Methods for Structure Analysis: X-Ray Diffraction Techniques. Crystallography and the World of Symmetry. 2008;113:57-75.

9. FL Ng, J Wei, FK Lai, et al. Metallic thin film depth measurements by X-ray microanalysis. Appl Surf Sci. 2006;252:3972-3976.

10. JL Pouchou. X-ray microanalysis of thin surface films and coatings. Mikrochim Acta. 2002;138(2):133-152.

11. W Habiger, C Stein. Thickness measurements of thin film:Comparison of techniques using characteristic $\mathrm{X}$-ray ratio techniques. Thin Solid Films. 1992;215:108-114.

12. J Padgurskas, R Rukuiža, V Jankauskas, et al. Tribological runningin investigation and surface analysis of copper coats made by electro-impulsive spraying. Surface and Coatings Technology. 2011;205(10):3328-3333.

13. F Kossivas, Ch Doumanidis, A Kyprianou. Thickness measurement of photoresist thin films using interferometry. Interferometry-Research and Applications in Science and Technology. Ed dr Ivan Padron. 2012.

14. M Conroy. Advances in thick and thin film analysis using interferometry. Wear. 2009;266(5-6):502-506.

15. Z Libo, B Shengxiang, W Rong, et al. Thin film thickness measurement using electron probe microanalyzer. Proc. IEEE Int. Conf. on Applied Superconductivity and Electromagnetic Devices. 2009.

16. LM Rybakova, LI Kuksenova. On the Change of Lattice Constant in the Surface Layers of Copper and Brass Caused by Friction. FizikaMetallov I Metalovedenie. 1975;39(2):362-366.

17. AH Cottrel. Dislocations and Plastic Flow in Crystals. UK: Oxford at the Clanderon Press; 1976. 